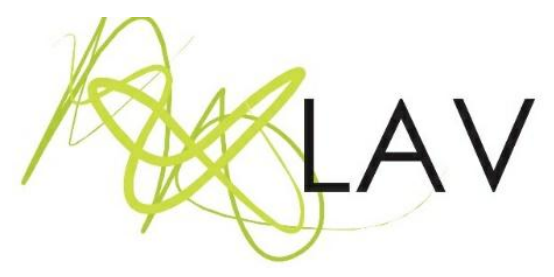

\title{
Do Corpo-Criança ao Corpo-Aluno: Estratégias de Controle e Possibilidades de Resistência pela Dança na Educação Infantil
}

\author{
From The Body-Child to the Body-Student: Control Strategies and Possibilities of \\ Resistance by Dance in Childhood Education
}

Aline Cristiane Ribeiro Ferreira dos Santos ${ }^{i}$ Universidade Estadual do Centro-Oeste

Aliandra Cristina Mesomo Liraii Universidade Estadual do Centro-Oeste

\begin{abstract}
Resumo
O artigo discute dados de investigação de mestrado, que teve entre seus objetivos problematizar a vivência da corporeidade no contexto da pré-escola, bem como considerar a dança como uma linguagem que proporcionaria uma formação humana que supera o controle dos corpos, empreendidos nos espaços educativos. O percurso teóricometodológico contou com a realização de observações do cotidiano institucionalizado em duas turmas de pré-escola e registros em diário de campo da configuração dos espaços, das relações e das práticas. O contexto investigado revelou-se marcado por relações de poder que anulam o corpo-criança e buscam instituir o corpo-aluno, tanto pela organização espacial e pelas ações desenvolvidas, principalmente, pelas verbalizações manifestas.
\end{abstract}

Palavras-chave: Educação Infantil, corpo, relações de poder, dança.

\begin{abstract}
The present article presents discussions on research data that had among its objectives to problematize the experience of corporeality in the context of preschool, as well as considering dance as a language that would provide human formation and overcome the control of bodies undertaken in educational spaces. The theoretical-methodological course included observations on the institutionalized daily life in two preschool classes, as well as field diary records of the configuration of spaces, relationships and practices. The investigated context proved to be marked by power relations that annul the body-child and seek to institute the body-student, both by the spatial organization and by the actions developed, mainly, by the manifested verbalizations.
\end{abstract}

Keywords: Early Childhood Education, body, power relations, dance. 


\section{Introdução}

A criança é movimento, seu corpo é linguagem, sua vida exploração; o corpo é presença viva nas relações com o mundo e interações com o outro (BONFIM; OSTETTO, 2019). A afirmação nos leva à compreensão de que as crianças falam de muitas formas, especialmente nos primeiros anos de vida, encaminhando para a defesa do corpo, assumido nesse estudo como potente, comunicador e ávido por descobertas.

O potencial da corporeidade no desenvolvimento infantil nos impele à necessidade de considerar que as instituições educativas promovam uma vivência saudável do corpo, com contextos, materiais e práticas que proporcionem situações e experiências desafiadoras, mas ao mesmo tempo seguras. Isso porque a dimensão corporal perpassa a constituição humana, e é especialmente importante para as crianças pequenas, sendo desejável organizar experiências variadas, flexíveis e interativas, as quais provoquem efetivo envolvimento.

Contudo, pesquisas na Educação Infantil explicitam um cotidiano marcado pelas exigências de um corpo controlado, constrangido em seus movimentos, limitado em suas interações, imobilizado em carteiras e mesas para exercícios no papel (CARVALHO, 2005; LIRA, 2008). No processo de escolarização, temos observado um atropelo da infância, que passa pelo controle dos corpos e, de maneira geral, tudo aquilo que a constitui, sendo o corpo-criança transformado no corpo-aluno. Estes binômios são propostos para nossa reflexão, pois buscávamos um termo que problematizasse o corpo enquanto criança, diferenciado do corpo enquanto aluno, ou seja, demarcando o papel da disciplina, do controle e das imposições institucionalizadas. O corpo-criança é concebido como a inteireza de sentimentos, envolvimento, participação e descobertas nos primeiros anos de vida (SANTOS, 2020).

Cabe registrar que a transformação do corpo-criança para corpo-aluno, via de regra, não se dá de forma tranquila, seja pela parte da criança, seja do ponto de vista institucional, prevalecendo formas de submissão verticais entre adultos e crianças, as quais almejam silêncio, acinesia e sujeição. É neste contexto, de inquietação com o que tem sido feito com nossas crianças nos anos finais da Educação Infantil, que esta investigação $^{1}$ se inseriu e buscou contribuir com suas reflexões, com olhar especial voltado aos espaços, as práticas e as verbalizações nesse contexto, bem como apresentamos a dança como um dos caminhos de resistência. O escopo teórico de nossa análise ancorou-se nas ideias do filósofo Michel Foucault (2005; 1999) dentre outros

\footnotetext{
1 Trata-se de um recorte da pesquisa de mestrado de Santos (2020).
}

Revista Digital do LAV - Santa Maria - vol. 14, n. 3, p. 83 - 106 - set./dez. 2021 ISSN 1983 - 7348 http://dx.doi.org/10.5902/1983734864933 
pesquisadores, tais como Luengo (2009), Strazzacapa (2001) e Veiga-Neto (2008), os quais, dentro de seus vieses, problematizaram o cotidiano escolar a partir dessa perspectiva.

Em um primeiro momento, escrevemos sobre a relação entre Educação Infantil e corporeidade, refletindo sobre as potencialidades das crianças e o papel do corpo no seu desenvolvimento. Na sequência, problematizamos algumas situações observadas na préescola e como se materializa o controle dos corpos e a produção de comportamentos desejados. Frente a este contexto e ancorada na discussão sobre a corporeidade infantil, na seção seguinte, elegemos a dança como uma possibilidade de resistir e experimentar uma vivência corporal potente que não anule o corpo-criança.

\section{Crianças, corporeidade e Educação Infantil: possibilidades e limites}

A partir do momento que nos inserimos no mundo, começamos a aprender por meio de interações, podendo elas ser com objetos, pessoas e tudo aquilo que nos cerca; esse processo atua na constituição humana, bem como os sujeitos que modificam os contextos em que vivem. Nesta troca, nas relações entre o corpo e o mundo, a corporeidade pode ser ativa, no sentido que explora, experimenta e aprende, ou passiva, quando corpo e sujeito se conformam, se ajustam ao que está dado. Desse modo, entendemos que a corporeidade é nosso modo de ser e estar no mundo.

Esta compreensão nos leva a considerar o corpo em sua dimensão social ativa ou conformada, o que significa levá-lo em conta para além da matéria física, que afeta e orienta as inúmeras relações e experiências dos sujeitos consigo mesmos, com os outros e com o mundo. Isto porque corpo e meio social são interdependentes e em cada ambiente, cada contexto, o corpo reage e se move de uma forma, seja por conveniência ou por obrigação em função das relações estabelecidas.

Nas crianças, a corporeidade se manifesta e se constitui especialmente por meio das brincadeiras, como uma atividade vivida nos diversos ambientes e de diferentes formas (KISHIMOTO, 2002), a depender do tempo, espaço e materiais disponíveis. Queiroz, Maciel e Branco (2006) registram que as brincadeiras das crianças, enquanto potência de vida, envolvem prazer, interação, exploração do meio, trazendo em seu bojo educação e formação.

Desde bebês, a corporeidade infantil se constitui nas ações de mamar, sugar, dormir, balbuciar, brincar com seu próprio corpo e, quando um pouco maiores, as 
brincadeiras representam a forma principal das crianças darem significado às coisas do mundo e apropriarem-se dele.

Ao carregar consigo um amplo leque de possibilidades de desenvolvimento, nos múltiplos aspectos da constituição humana, o brincar representa a forma mais apropriada e encorajadora da criança estar no mundo, sendo importante dar espaço e proporcionar condições para que isso aconteça, tanto nos contextos familiares quanto nos institucionalizados, considerando os sujeitos infantis em sua potencialidade e integralidade. É por meio dele que o corpo-criança é desafiado, convocado a se posicionar, promovendo experimentações singulares e determinantes ao desenvolvimento infantil.

Kishimoto (2002), ao falar sobre a inteireza do corpo da criança que se integra na representação e no brincar, observa que este era possível nas ruas, quintais, e nestes espaços, a criança se socializava e aprendia novas brincadeiras. O cotidiano regulado e de confinamento da atualidade deixa poucas brechas para a criança escapar dos compromissos, como também para os sujeitos infantis dos grupos economicamente marginalizados na realidade de trabalho e carências de todas as ordens, que podem comprometer o brincar.

Reconhecemos, pois, que a criança vive sua infância de formas diferentes em função das experiências que participa e das relações que estabelece. Como lembra Kohan (2003, n.p.) "Notemos que a infância não é apenas uma questão cronológica: a infância é uma condição da experiência [...]", é o tempo da vivência, do mergulho no mundo, que toca as crianças de maneiras distintas em função do que vivem.

Desse modo, falar de infância é considerar essa fase da vida sob a ótica das descobertas, da fascinação, da disposição corporal para se aventurar a aprender em múltiplas áreas, das diferentes formas de comunicação, incluindo a expressão corporal, o brincar, o falar, o agir, dentre outras experimentações. Mas, também, como uma categoria marginalizada, alvo de controles e disciplinarização por meio de diversos esteios sociais. O aprender por si próprio e com os outros, agregado à curiosidade, rege as ações infantis, e é exatamente essa natureza desconhecida que as torna motivo para o disciplinamento na escola, pois o imprevisível deve ser evitado, já que a novidade pode desestabilizar.

Na contemporaneidade, a infância vivida pelas crianças tem cada vez mais se caracterizado por um tempo institucionalizado nos Centros de Educação Infantil e escolas. Experiências e estudos como os de Lira (2008) e Carvalho (2005) têm 
demonstrado a prevalência de um cotidiano marcado pelo controle e disciplinarização, com privilegio para as atividades de leitura e escrita em detrimento ao trabalho com outras linguagens. Nesses contextos, as crianças têm encontrado dificuldades de viver sua infância com qualidade, uma vez que são 'atropeladas' por uma série de expectativas e rituais que as transformam em alunos, como foco no controle dos corpos, que se outorga de diversas formas.

O corpo subjugado, capturado pelas diferentes instâncias e ações sociais é desde muito cedo alvo da mídia, da publicidade, dos interesses capitalistas. No âmbito escolar, segundo Colello (1993), o corpo da criança começa a ser formatado desde a entrada dos sujeitos infantis nas instituições educativas, uma vez que do ponto de vista escolar e do professor, ações como brincar, falar ou movimentar-se não correspondem às normativas pedagógicas de disciplina, silêncio e imobilidade. A partir desse campo de ação que atua sobre corpos e mentes, entendemos, para efeito desse artigo, que as instituições educativas operam uma transformação do corpo-criança em corpo-aluno.

Cabe registrar que a transição do corpo-criança para o corpo-aluno, na maior parte dos casos, acontece de forma conflituosa, com resistências, fugas, especialmente pela parte da criança. Historicamente, a escola foi descrita como uma instituição disciplinar assentada no controle e na vigilância de comportamentos e pensamentos, com formas eficazes de exercício do poder, buscando a (con)formação de corpos dóceis desde a mais tenra idade (FOUCAULT, 1999). É fato que o domínio do corpo-criança não se faz apenas pela via escolar, uma vez que socialmente temos instaurado um conjunto de aparatos, especialmente com a tecnologia, que faz este controle e impõe formas de vigilância e penalidades, tendo o corpo como alvo.

Quando pensamos em um corpo docilizado não estamos nos remetendo somente a um corpo imóvel, mas sim ao corpo produtivo, formatado na instituição disciplinar em sua máxima potência, aquele que responde aos estímulos prontamente, que não subverte, embora a resistência seja sempre possível, como nos ensinou Foucault (1999).

A Educação Infantil responsável pelo atendimento, em creches ou instituições equivalentes, para crianças de 0 a 3 anos de idade e em pré-escolas, para as de 4 e 5 anos. É dever do Estado e direito de todas as crianças. A legislação e os documentos orientadores dessa etapa do ensino (BRASIL, 2009; 1996) destacam como objetivo principal o desenvolvimento infantil nos múltiplos aspectos, por meio da consolidação de práticas pedagógicas ancoradas nas interações e brincadeiras. 
As crianças aprendem por diversificados meios e interações e, comumente, por experimentação, ou seja, ao tocar, sentir e usar a imaginação vivenciam a realidade ao seu redor. Nas instituições educativas, o aprisionamento da corporeidade explicita que a mente é priorizada e o corpo menosprezado, uma vez que quanto maiores as crianças mais as atividades se restringem ao preenchimento de folhas e apostilas, com o corpo controlado.

Esse formato escolarizado entra em choque com a compreensão de que a conexão da criança com o mundo se faz especialmente por meio do corpo, em vivências efetivas com os pares, os adultos e na exploração do mundo a sua volta. Uma vez que os pequenos enxergam o mundo com o corpo todo, eles necessitam pegar objetos, reconhecer sua textura, descobrir possibilidades, aventurando-se na tarefa do conhecimento. Contudo, nem sempre essa compreensão encontra morada na organização das práticas pedagógicas.

Bonfim e Ostetto (2019) problematizam o apagamento dos corpos infantis no cotidiano da creche, com rotinas focadas na realização de atividades fragmentadas e corpos contidos. As autoras ressaltam que as práticas impõem limites aos corpos e empobrecem as experiências e o corpo contido, negado desde os primeiros anos de vida, acaba definhando, acomodando-se dentro daquele formato esperado para o aluno.

Foucault (2005; 1999) explicita como a sociedade disciplinar controla as ações, mas ao mesmo tempo atua para produzir comportamentos, ou seja, as relações de poder são em parte restritivas, mas em sua essência produtivas. Este caráter de produtividade é importante de ser considerado, pois se explicita de diferentes maneiras no contexto educativo das crianças pequenas, especialmente na organização e no uso dos espaços, nos olhares e verbalizações, nas práticas destituídas de sentido e padronizadas.

Como registram López-López e Galdino (2020, p. 129) "A escola deveria ser o lugar onde as possibilidades de se relacionar com o mundo fossem ampliadas e não reduzidas a uma única grande caixa com formas idênticas onde todos deverão se encaixar. Cada corpo é único e suas formas de se expressar: infinitas! "Segundo elas, considerar a potência do corpo pode levar a caminhos de uma educação mais viva, uma vez que os corpos infantis têm vontade de vida, resistem.

O corpo que não se acomoda é identificado na pesquisa desenvolvida por Santos, Guimarães e Arenhart (2019, p. 518), as quais destacam que embora em menor medida o corpo afronta, resiste, subverte:

Revista Digital do LAV - Santa Maria - vol. 14, n. 3, p. 83 - 106 - set./dez. 2021 ISSN 1983 - 7348 http://dx.doi.org/10.5902/1983734864933 
Nas relações corporais das crianças com os adultos, destacamos também a dimensão da resistência ao instituído pelo adulto. $\mathrm{O}$ corpo que se coloca, que contraria, que desobedece a alguns pedidos das professoras. Um corpo que é movimento e busca movimentar-se a todo o momento.

Segundo as autoras, nesse intento, os corpos dos professores também são convocados a se movimentar e a brincar, contudo, resistem em uma postura de não disponibilidade para tal, restringindo-se a encaminhamentos protetivos ou de correção. Superar essa condição impõe desafios à docência, subvertendo o lugar de poder do adulto nas relações educativas.

Como procuramos discutir, o controle dos corpos não se dá exclusivamente via escolar, mas nas instituições educativas que ele se intensifica, ao se fazer presente cotidianamente, seja pelas verbalizações, pela organização dos espaços ou pelas práticas instituídas. A partir do reconhecimento da importância da vivência da corporeidade nos primeiros anos de vida, voltamos nosso olhar para a realidade institucionalizada, como forma de reconhecer como isso ocorre.

\section{A pré-escola e os corpos controlados: do corpo-criança ao corpo-aluno}

Como lembra Laval (2020), Foucault nos convoca a questionar os fenômenos de dominação, analisá-los, mostrar sua lógica, reconhecer como operam. Ao focar nos processos e ações escolares que sujeitam o corpo da criança ao seu domínio para obter um 'bom aluno', procuramos analisar as formas de vigilância e produtividade que têm o corpo-criança como alvo, desde a organização do espaço até as verbalizações, olhares, restrições vividas.

Veiga-Neto $(2008$, p. 145$)$ registra que a escola se traduz "[...] como a mais importante instituição capaz de moldar disciplinarmente os indivíduos que ela toma para si $[\ldots] "$, uma vez que as crianças vivem grande parte da infância institucionalmente. No cotidiano, o autoritarismo se mostra geralmente na figura do professor que tende a impor uma perspectiva adultocêntrica, que negligencia as crianças e suas especificidades.

A discussão deste item é fruto da pesquisa de mestrado (SANTOS, 2020) realizada entre os anos de 2019 e 2020, com o objetivo de problematizar as práticas pedagógicas voltadas para a vivência da corporeidade na pré-escola. O percurso metodológico contou com a realização de observações com registros em diário de campo, em duas turmas de

Revista Digital do LAV - Santa Maria - vol. 14, n. 3, p. 83 - 106 - set./dez. 2021 ISSN 1983 - 7348 http://dx.doi.org/10.5902/1983734864933 
pré-escola de duas instituições públicas ${ }^{2}$, de um município de médio porte na região central do Paraná. O acesso aos dados deu-se por meio de seis observações em cada turma, uma vez por semana, sendo privilegiada a descrição dos espaços físicos e das relações estabelecidas entre professores e crianças, com especial atenção para as atividades desenvolvidas, as verbalizações emitidas e para a vivência da corporeidade nesse contexto. No município pesquisado, as turmas de pré-escola foram deslocadas, nos últimos anos, para instituições que antes atendiam apenas crianças do Ensino Fundamental, sendo uma estratégia adotada para cumprir com a obrigatoriedade de matrícula instituída pela Lei n. 12.796 de 2013.

A ampliação da escolaridade obrigatória para a pré-escola é problematizada por Lira, Drewinski e Sapelli (2016), que refletem sobre as implicações das estratégias adotadas pelos municípios para atender as crianças, com direito a frequentar apenas jornada parcial, em instituições sem estrutura física adequada e com professores concursados para atuar no Ensino Fundamental. As autoras salientam que, como forma dos municípios estarem em conformidade com a lei quanto à oferta das vagas, os pequenos acabam sendo penalizados, juntamente com suas famílias, uma vez que o direito a uma Educação Infantil de qualidade fica comprometido.

$\mathrm{Na}$ instituição I, a sala do pré I era ampla, atendia 22 crianças pela manhã e estava organizada em dois lados, sendo que ambos contavam com um tatame ${ }^{3}$. Havia em uma das paredes um espelho e noutra um alfabeto, que ia de um lado a outro; observava-se ainda calendário, cartaz do tempo, lista de combinados, lista de presença (com os crachás) e cabides para as mochilas. Havia também um terceiro tatame, que comportava uma casinha para as crianças brincarem. O mobiliário de mesas e cadeiras era adequado ao tamanho das crianças, que agrupadas formavam alguns conjuntos que ficavam do lado esquerdo; no lado direito ficavam três mesas grandes com bancos compridos para as crianças se sentarem juntas e realizarem atividades coletivas, sendo o lugar de uma 'reservada' com uma etiqueta com o nome, indicando onde sentar. A instituição contava com um parque externo, mas que estava interditado, não podendo ser usado.

$\mathrm{Na}$ instituição II, a sala observada era pequena para abrigar as 20 crianças atendidas no período matutino. Contava com quatro mesas grandes, sendo três usadas pelas crianças e uma pela professora, que sentava em uma cadeira de tamanho pequeno; nas mesas, a professora organizava as atividades em rodízio, enquanto um

\footnotetext{
${ }^{2}$ Aqui nomeadas de instituição I e instituição II.

${ }^{3} \mathrm{~A}$ tarde era usada por outra turma de pré I e conforme explicado pela professora em cada lateral da sala, nas paredes, havia cartazes e materiais guardados para as turmas.
}

Revista Digital do LAV - Santa Maria - vol. 14, n. 3, p. 83 - 106 - set./dez. 2021 ISSN 1983 - 7348 http://dx.doi.org/10.5902/1983734864933 
grupo fazia atividades no papel, os outros brincavam com jogos distribuídos por ela. Nas paredes um alfabeto incompleto (pois não cabia inteiro, segundo a professora), materiais de limpeza em um canto, um armário para guardar os materiais usados pelas crianças. A pintura da sala era em cor bege, e tudo que estava nela etiquetado; contava ainda com espelho e cabides para pendurar mochilas. Um tapete situado em um dos cantos ficava embaixo do calendário e da janelinha do tempo, seguida da chamada de crachás. Nessa mesma parede havia um espaço para pendurar atividades e cartazes com aniversariantes e combinados, decorados com personagens da turma da Mônica. Em outra parede havia uma prateleira com compartimentos para separar os materiais de uso diário e, ao lado, um cesto com brinquedos sobre um tapete de canto. Cabe registrar que essa instituição não dispunha de parque, sendo o intervalo das crianças passado geralmente em área externa cuja cobertura de solo predominava o concreto.

Encontramos, nos contextos das turmas observadas, diversificadas estratégias para controlar comportamentos que se refletem diretamente no corpo. Segundo Foucault (1999), quando o processo de disciplinar é bem-sucedido o sujeito se torna dócil, submisso e útil para o meio social. Na escola, o controle disciplinar desempenha a função de prever, ajustar ou suprimir comportamentos, inclusive antes de se materializarem. Nos dedicamos, no escopo desse artigo, a problematizar as intervenções verbais, a organização dos espaços e as práticas pedagógicas, reconhecendo seus investimentos disciplinares nos corpos infantis.

O governo dos corpos se faz inicialmente pelas verbalizações, mas é internalizado e atua mentalmente, uma vez que esses rituais se repetem cotidianamente. A fila nas instituições educativas é adotada sob o argumento da organização, entretanto, acaba por conformar os corpos a uma vivência extremamente controlada, associada a sanções caso haja descumprimento. As regras repetidas diariamente rotinizam o corpo, a ponto de as crianças começarem a agir de modo autômato, sendo continuamente relembradas pelas professoras:

'Já disse para colocarem as mochilas e blusas no cabide, façam isso e voltem a sentar aqui. Vamos, vamos' (DIÁRIO DE CAMPO, INSTITUIÇÃO I, 2019).

'Quero perninha de índio, as mãos devem estar cruzadas ou em cima da barriga ou na perna' (DIÁRIO DE CAMPO, INSTITUIÇÃO II, 2019).

As falas de comando não se estendem apenas ao controle dos movimentos do corpo, mas também à contenção da fala, como fica evidente nas transcrições a seguir das verbalizações das professoras. A linguagem empregada e o tom de voz acentuam as

Revista Digital do LAV - Santa Maria - vol. 14, n. 3, p. 83 - 106 - set./dez. 2021 ISSN 1983 - 7348 http://dx.doi.org/10.5902/1983734864933 
orientações e chamam a atenção das crianças, sendo o silêncio colocado como regra a ser cumprida, cujo êxito promove premiação:

'Vamos, vamos. Andem, façam fila e fiquem quietas' (DIÁRIO DE CAMPO, INSTITUIÇÃO II, 2019).

'SHHHIIIIII, eu não preciso olhar pra saber que vocês estão conversando' (DIÁRIO DE CAMPO, INSTITUIÇÃO II, 2019).

A professora diz: 'Eu não gosto de conversa, eu gosto de silêncio' (DIÁRIO DE CAMPO, INSTITUIÇÃO II, 2019).

Acompanho a escolha da ajudante do dia, Karyn, que segundo a professora 'foi escolhida por ser a mais quietinha' (DIÁRIO DE CAMPO, INSTITUIÇÃO I, 2019).

Como lembram Barbosa e Borba (2011, p. 83),

O silêncio imposto pela escola, pelo professor é algo que, muitas vezes, pode deformar e podar a personalidade do indivíduo que está se formando. Como ato disciplinador, é um dos instrumentos que o professor tem ao seu alcance para obter o controle sobre os alunos, fazendo com que a sala de aula tenha ordem e que somente o mestre tenha a palavra e o aprendiz a escute.

Compreendemos que em muitos momentos é importante que as crianças se mostrem disponíveis para a escuta, mas a troca de informações, as relações, fazem parte do processo educativo, que prima pela interação e participação ativa, contudo, não é o que temos presenciado dentro das escolas. De modo geral, nas turmas observadas, percebemos que, quando as crianças queriam participar, falar e contar de si e de suas experiências, acabavam sendo repreendidas pelas professoras, como na situação abaixo:

'Silêncio! Quem está contado a história sou eu e não vocês. Vocês só escutam' (DIÁRIO DE CAMPO, INSTITUIÇÃO II, 2019).

Reconhecemos que as vocalizações trazem em seu bojo "[...] ao mesmo tempo, efeitos de prescrição (em relação ao que se deve fazer) e efeitos de codificação (em relação ao que se deve saber)" (CARVALHO, 2005, p. 25). A fala do adulto tem um papel preponderante nesse processo, pois anuncia, emana autoritarismo, atuando larga e incisivamente na construção de um corpo desejável de aluno. Interpretamos, assim, as verbalizações repetidas como o exercício do poder que se dá nessas relações cotidianas, difuso e capilarizado como aprendemos com Foucault (1999), que usa menos da força e mais do convencimento, da coação, da vigilância, das sanções para produzir os comportamentos desejados.

Nessa linha de pensamento, Sabot (2017) lembra que o exercício do poder geralmente se apresenta de forma não coercitiva, pois visa interiorizar comportamentos

Revista Digital do LAV - Santa Maria - vol. 14, n. 3, p. 83 - 106 - set./dez. 2021 ISSN 1983 - 7348 http://dx.doi.org/10.5902/1983734864933 
pela prática repetida, dando-Ihe pouco a pouco a forma de hábitos internalizados, o que também observamos:

Ao término da atividade as crianças guardam os materiais, fecham as mochilas e fazem fila para sair para o recreio, a professora nem precisou pedir (DIÁRIO DE CAMPO, INSTITUIÇÃO II, 2019).

Paulatinamente, o controle é internalizado, os sujeitos se autopoliciam, autogovernam e, ao refletir sobre as verbalizações, observamos que essas não apenas corrigem o corpo de maneira igual, mas o moldam a partir das orientações às crianças de como devem andar, sentar, fazer as tarefas, quando e onde podem falar e se movimentar, com vistas ao aproveitamento do tempo e das ações.

Além da disciplinarização e do controle impostos aos corpos pelas verbalizações, outro aspecto problematizado foi a organização do espaço e como ele pode atuar na anulação dos corpos infantis. A atenção ao espaço como educador parte da premissa de que ele não é neutro e atua sobremaneira na configuração dos processos educativos. Essa compreensão supera a visão do espaço apenas como decorativo para assumir o importante papel educativo que depende de sua organização, do mobiliário, dos materiais disponibilizados (ou não!). Horn (2017) destaca a importância de que os espaços sejam dispostos de modo a promover a participação infantil, com privilégio para as brincadeiras e interações. Todavia, o espaço também pode ser restritivo a partir do que permite ou não fazer, das experiências que promove.

Nos contextos investigados, a ausência do parque ou a proibição de uso dele reforçam a compreensão de que brincar é perda de tempo, de que para as crianças da pré-escola é lugar de aprender em sala e com atividades no papel:

As crianças caminham para o refeitório; a última criança pede para que eu a erga para ela poder ver o parquinho e ela diz 'Ali é nosso parque, mas não pode ir lá' (DIÁRIO DE CAMPO, INSTITUIÇÃO I, 2019).

Nesta fala da criança, pode-se identificar não apenas o impacto dos modos de controle e conformação ao qual seu corpo se encontra submetido, mas também a consciência de não pertencimento àquele lugar que deveria abrigá-la e acolhê-la.

As Diretrizes Curriculares Nacionais para a Educação Infantil (BRASIL, 2009) indicam a necessidade de organizar espaços que promovam a não separação das dimensões expressivas das crianças, integrem as ações de cuidado e educação e a participação infantil. Dessa maneira, o espaço físico torna-se um elemento importante de

Revista Digital do LAV - Santa Maria - vol. 14, n. 3, p. 83 - 106 - set./dez. 2021 ISSN 1983 - 7348 http://dx.doi.org/10.5902/1983734864933 
promoção do acolhimento, e, voltado para as brincadeiras, com vivências corporais tanto no contexto interno como externo das instituições. Nas salas das turmas investigadas observamos materiais lúdicos acessíveis escassos, os poucos jogos e brinquedos dependiam da permissão do adulto para serem utilizados e, geralmente, isso acontecia com o pretexto de trabalhar algum conteúdo.

Para Silva e Santos (2009, p. 9-10) é fundamental que as crianças possuam espaços para brincar, pois são nestes lugares que produzem cultura, inventando ou recriando brincadeiras:

É importante que sejam oferecidos às crianças espaços de transmissão de cultura para que elas possam brincar e, assim terem oportunidades de criação, pois quando a criança brinca, reinventa cenas do cotidiano que a marcam, construindo sua própria história [...]. Ao movimentar o seu corpo, a criança inventa brincadeiras e, assim, constitui o seu eu, sua imaginação e seus pensamentos. Quanto maior for a qualidade do brincar maior será o desenvolvimento.

Perrotti (1990, p. 18) reflete sobre a organização do espaço pensado de forma adultocêntrica, que parte do pressuposto que a criança deve ser socialmente passiva: "Pensamos sempre na criança recebendo (ou não recebendo) cultura, e nunca na criança fazendo cultura ou, ainda, na criança recebendo e fazendo cultura ao mesmo tempo". Um espaço que não é vivido, acessado, impõe ao corpo a resignação, a imobilidade. Em muitas situações, nas duas turmas observadas constatamos esse cenário, em que as pequenas resistências infantis de subversão eram rapidamente silenciadas.

O papel do espaço no controle dos corpos se manifestou, ainda, na prevalência de atividades em sala e pela pouca interação das crianças nesses locais. As paredes ocupadas por cartazes feitos por adultos, com materiais plastificados como E.V.A. e personagens da cultura midiática, colaboram para construir um ambiente artificializado, separado da vida, formatado para a vida escolar, que é pouco atrativa ao imaginário infantil.

Quanto às práticas pedagógicas, predominaram nos dois contextos, como já dissemos, o uso do espaço interno, mais especificamente a sala, com o acesso a espaços externos ou diferentes em algumas aulas (Laboratório de informática, quadra para Educação Física), e privilégio de atividades em folhas xerocadas para completar. Reconhecemos que do ponto de vista institucional, o tempo em sala tem um valor revestido da intencionalidade pedagógica, diferente daquele a ser vivido no parque e na área externa, cuja percepção assume a ideia de passatempo, e não de aprendizado. 
Prevalece o entendimento de que sentadas e fazendo atividades no papel as crianças estariam aprendendo e no parque brincando, estariam em recreação, não reconhecida como atividade pedagógica. Confinar o aprender à sala obriga que os corpos sejam docilizados, que aprendam a ficar quietos, obedientes, solícitos, disciplinados.

Até hoje a escola não é pensada e nem organizada fisicamente para acolher a criança e integrá-la a este ambiente que também é seu, dando a mesma o sentimento de pertencimento. Assim, o que normalmente acontece é que os alunos são apresentados a uma estrutura física escolar de padrão nacional, a qual se espera que todas as crianças se adaptem, sem levar em consideração as suas individualidades (SERODIO; STEINLE, 2016, p. 130).

Percebe-se como a organização espacial pode anular o papel da Educação Infantil de proporcionar experiências enriquecedoras de ampliação das vivências corporais, angariadas essencialmente pelo brincar. É pelo brincar e pelas diferentes formas de expressão, usando o corpo pela fala, expressões e gestos que a comunicação infantil se estabelece, amplia e enriquece, sendo que uma corporeidade vivida de forma sadia e poética preserva o corpo-criança.

Na contemporaneidade, a escola está proibida de fazer uso de violência física, mas usa de estratégias que produzem comportamentos a partir da internalização de regras e normas: "A autovigilância, a aplicação pelo sujeito nele mesmo de um certo número de modelos de comportamento, permite, assim, reduzir os controles externos e atenuar o dispositivo sem prejudicar sua eficácia, mas, ao contrário, melhorando-a" (SABOT, 2017, p. 22).

A criança, embora resista em muitos momentos, se adapta à constrição e produz comportamentos adaptados. Em geral, as ações se orientam pela vigilância do professor, mas também podem se dar pelo papel atento dos colegas, pelo reforço das regras e combinados (muitas vezes expostos de forma escrita na sala), os quais são repetidos e internalizados pelas crianças, evidenciando que as práticas pedagógicas investem no corpo infantil para obter o corpo-aluno.

O município, ao transferir as turmas de pré-escola para instituições que atendem crianças do Ensino Fundamental, antecipou às crianças de 4 e 5 anos de idade uma formação e exigências já praticadas para as crianças maiores, ou seja, cada vez mais cedo os corpos infantis são institucionalmente capturados e docilizados, em um processo naturalizado. Vale registrar que a lei permite o atendimento da Educação Infantil em escolas que trabalham com os primeiros anos do fundamental, desde que sejam respeitadas as adequações de organização do espaço e implementadas práticas que 
considerem a especificidade das crianças de 0 a 6 anos de idade, cujos atendimentos têm finalidades próprias, não subordinados aos objetivos do Ensino Fundamental.

Um aspecto que chamou nossa atenção nas turmas que observamos foram os 'combinados' expressos em listagem escrita de comportamentos permitidos e proibidos. Incluíam orientação para prestar atenção 'na aula', levantar a mão para falar, não gritar, usar as 'palavrinhas mágicas', não sair da sala sem permissão, dentre outros. A escola se vale na organização de suas práticas de formas variadas para introduzir normas e formatar comportamentos e corpos.

Como registra Oliveira (2011), muitas culturas se utilizam das músicas para impor conformidade às normas sociais, e na escola não é diferente. As 'musiquinhas' de ordem são usadas para acalmar e dominar as crianças, como revelou um dos professores entrevistados na pesquisa da autora, o qual mencionou ser mais agradável você dar uma ordem por meio de uma música de comando.

A partir de Foucault (1999) compreendemos que o poder disciplinar pode ser mais explícito ou diluir-se nas relações estabelecidas, como por exemplo as músicas de rotina, que trazem uma atmosfera de graciosidade e infantilidade, sendo aprazíveis e aceitáveis, são estratégias para modelar o corpo-aluno. Presenciamos um conjunto diversificado de músicas de comando para bem cumprimentar, comer de boca fechada, fazer silêncio, caminhar lentamente, atuando sobre o conjunto da população infantil. $\mathrm{Na}$ instituição II isso foi mais evidente, pois todos os dias antes de irem para as salas as crianças ficavam no pátio, em fila, para ouvir a fala da gestora e músicas, inclusive religiosas.

Para Luengo (2009), ações generalizadas e largamente utilizadas nos contextos educativos não permitem que o professor veja a criança como um ser único, atravessado historicamente, cujas experiências vividas serão apropriadas de modo singular. A compreensão da criança como aquela cujos comportamentos precisam ser educados, moldados, corrigidos, ignora a capacidade de pensamento e participação infantil, não considera seus modos de explorar e imaginar.

Nas práticas acompanhadas, a imobilidade faz parte do funcionamento escolar, e a liberdade de se expressar, correr, brincar e de ser criança é tratada como uma recompensa para aquela que se manteve adaptada, que se comportou. Strazzacapa (2001, p. 70) lembra que

O movimento corporal sempre funcionou como uma moeda de troca. Se observarmos brevemente as atitudes disciplinares que continuam sendo utilizadas hoje em dia nas escolas, percebemos

Revista Digital do LAV - Santa Maria - vol. 14, n. 3, p. 83 - 106 - set./dez. 2021 ISSN 1983 - 7348 http://dx.doi.org/10.5902/1983734864933 
que não nos diferenciamos muito das famosas 'palmatórias' da época de nossos avós. Professores e diretores lançam mão da imobilidade física como punição e da liberdade de se movimentar como prêmio.

Essa visão limitada comanda uma tarefa de padronizar comportamentos, modos de pensar e se a escola trabalha a partir de padrões do que entende ser normal e aceitável, irá, a partir disso categorizar, enquadrar, classificar e julgar as crianças tidas como desajustadas.

Assim, o corpo-criança vai sofrendo sanções, adequações e perecendo, dando lugar ao corpo-aluno, ajustado, resignado. O que inicialmente era aparelhamento, acaba por atrofiar e sufocar para ganhar a forma desejada. Pensando com Foucault (1999), compreendemos que a disciplinarização torna o corpo-criança em um corpo-aluno, lobotomizado, um corpo dócil, submetido.

A criança vai perdendo os seus sentidos, quando já não pode mais usá-los. A sua linguagem corporal é roubada, quando ela não pode mais manifestar as dores e os sabores por meio do corpo ou da fala; ao se sentir presa a um sistema que a rejeita, ela passa a internalizar as disciplinas e a aceitar o que Ihe impõem (LUENGO, 2009, p. 126).

O desejável é uma criança sentada, olhando para frente e se possível sem falar, como forma de controlar as interações, bem como as verbalizações. Esse controle absoluto do corpo, para a criança é um massacre físico que atrofia seus movimentos. Segundo Luengo (2009, p. 124) o objetivo é dar prioridade ao sistema reprodutivo, próprio da sociedade capitalista:

Com o desejo obstinado de produzir, próprio da sociedade capitalista, a escola se destina ao desenvolvimento de um espaço em que a prioridade seja a produtividade e, ao mesmo tempo, a obediência às leis, que na maioria das vezes não vem através de uma conscientização de cidadania, porém, num modo alienante, que destrói o aspecto crítico e questionador da infância, com o objetivo de priorizar o sistema produtivo.

Ao acompanhar e problematizar as práticas pedagógicas voltadas para o exercício da corporeidade, foi possível constatar que o espaço, as interações e as verbalizações presentes nos dois contextos investigados concorrem para um ajustamento e controle dos corpos infantis. Reconhecemos, pois, que as experiências infantis não têm sido vividas em sua integralidade, mas limitadas aos olhos do adulto, mediadas por seu controle. 
Diante desta realidade inquietante e limitadora, ao mesmo tempo que produtiva, que imprime suas marcas nos corpos das crianças, procuramos pensar em possibilidades de resistir, sendo a dança uma linguagem bastante apropriada para tal. Defendemos que por meio da arte, em sua linguagem mais corporalmente expressiva, a dança, podemos proporcionar momentos de vivência da corporeidade que incluem a brincadeira e a criação.

\section{Do recolhimento do corpo à soltura: a dança como contraposição à acinesia}

O corpo-criança cheio de vida, energia e movimento, defronta-se com a exigência de imobilidade e repetições para a incorporação dos gestos, dos hábitos, dos comportamentos ensinados e esperados, formatando o corpo-aluno, consequência do dualismo que alicerça as escolas formais, o qual valoriza em demasia o ensino analítico em detrimento ao sistêmico (MARQUES, 2007). A criança, entusiasta e cheia de potência, conforma seu corpo nos moldes da disciplina no espaço escolar que funciona ancorado em relações de poder, cuja vigilância empregada pelos adultos se soma ao autocontrole e ao crivo de seus pares.

O viés foucaultiano nos ajuda a reconhecer de que forma os corpos infantis são vistos, formados e controlados nas instituições educativas, como também nos sinaliza possibilidades de resistência. A arte, a partir de sua potência transformadora e para efeitos desse estudo, é vista como a oportunidade de vivência de uma corporeidade infantil sadia, cujo mote seja a expressividade. Uma vez que a escola tem trabalhado para promover a acinesia infantil, a arte surge como alternativa para tentar manter vivo o corpo-criança, buscando superar modelos estáticos de educação da expressividade corporal. Em especial a dança, que não se limita a modelos pré-estabelecidos e que quando orientada pelos estudos do corpo de Rudolf Laban (1879-1958) acerca de sua existência no contexto educativo, se mostra como caminho que permite o movimento livre do corpo, não se limitando apenas ao momento artístico. O pesquisador do movimento, bailarino e coreógrafo, que estudou o corpo e as possíveis relações entre a mente e o espaço, Rudolf Laban ${ }^{4}$ traz importantes contribuições para pensar a dança na escola. Ele defendeu que o movimento é uma forma de expressão e comunicação dos sujeitos, ou seja, é a possibilidade de pensar.

Compreendemos aqui a importância da dança como fomentadora da criatividade,

\footnotetext{
${ }^{4}$ Rudolf Laban nasceu em Pressburg, atual Bratislava, em 15 de dezembro de 1879 e faleceu na Inglaterra em 1 de julho de 1958. Foi um dançarino, coreógrafo, teatrólogo, musicólogo, intérprete, considerado como o maior teórico da dança do século XX.
}

Revista Digital do LAV - Santa Maria - vol. 14, n. 3, p. 83 - 106 - set./dez. 2021 ISSN 1983 - 7348 http://dx.doi.org/10.5902/1983734864933 
bem como acesso para um desenvolvimento integral das crianças de 0 aos 6 anos, visto que nessa fase amplia-se a capacidade sensorial e motora. Acreditamos que a partir da dança é possível que os pequenos possam vivenciar com seus corpos experiências emocionais e lúdicas, uma vez que

É uma ferramenta favorável ao autoconhecimento da criança e ao conhecimento do outro, à expressão da psique partindo de sua dimensão corporal, ampliando seus limites, suas possibilidades e desafios. Dançar é movimentar-se, expressar as profundezas do ser. As crianças coreografam suas vidas, delineando com seus corpos, suas alegrias, seus esforços, suas brincadeiras. Pois é um movimento que surge delas e se expressa a todo momento, girando, correndo, batucando, pulando (WAHBA; SCHMITT, 2013, p. 430).

É importante considerar que devemos evitar o utilitarismo, o qual pode perpassar as escolhas dos professores, pois a dança não se presta a objetivos previamente delimitados, contudo, não podemos afastá-la como conteúdo: "[...] a dança como forma de arte, está engajada com o sentimento cognitivo e não somente com o afetivo" (MARQUES, 2007). Segundo a autora, é por meio dos corpos dançantes que os processos cognitivos se integram aos processos mentais, permitindo compreender o mundo de maneira diferenciada artisticamente e esteticamente.

A potência da dança, apresentada em forma de brincadeira, pode promover experiências corporais diversificadas de expressão e de comunicação para as crianças, e ao potencializar o conhecimento de si propicia a exploração de novos sentidos, oferecendo momentos de liberdade e criação. Aceitamos como verdadeiro que dançar é viver o corpo, a vida em sua plenitude, se bastando por si só e não precisando estar atrelada a um objetivo ou conteúdo. Se essa última intenção tomar corpo, então, se torna instrumento usado para angariar êxito sobre algo, perdendo sua essência.

Estimular a dança livre, criativa, que busca valores educativos, sem disciplinar, é proporcionar a vivência do corpo-criança, a potência dos movimentos e criações na infância, também colaborando para formar indivíduos mais sensíveis às diversidades. A dança educativa é a que melhor contempla as propostas lúdicas e criativas para a Educação Infantil, ao permitir às crianças aprender e experimentar movimentos, ampliar relações interpessoais: "Esta consideração se expressa na riqueza das formas do movimento liberado, nos gestos, nos passos, assim como naqueles que o homem contemporâneo utiliza em sua vida cotidiana" (LABAN, 1990, p. 14-15). As brincadeiras e a dança, compreendidas como arte, não são da perspectiva do laissez-faire, uma vez que são essenciais para bem viver a infância de maneira saudável e com uma compreensão 
melhor do seu entorno. Marques (1990) esclarece que é pelo nosso corpo que compreendemos onde estamos e onde queremos chegar.

A dança como linguagem artística possui a qualidade que dá lugar ao movimento, contudo, "As aulas de dança podem ser verdadeiras prisões dos sentidos, das ideias, dos prazeres, da percepção e das relações que podemos traçar com o mundo" (MARQUES, 2007 , p. 26). Infelizmente, o cotidiano pedagógico expõe situações em que a dança existe de modo engessado, com movimentos coreografados, e geralmente como apresentação em datas festivas, revelando uma existência limitada e pouco agregadora ao desenvolvimento infantil.

Por outro lado, a dança na Educação Infantil pode se materializar em experiências significativas ao ampliar o reportório cultural, aguçar a criatividade, bem como a curiosidade própria das crianças. A função do professor é a de possibilitador, aquele que ajuda as crianças criando para elas não sequências prolongadas e dificultosas, mas sim oportunidades de movimentação que fomentem o movimento interior da criança.

Almeida (2011, n. p.) descreve as experiências em dança com crianças como fundamentais para um desenvolvimento de si agregado ao conhecimento do outro, proporcionando a consciência corporal que se desenvolve quando criança e continua sucessivamente até o fim da vida:

[...] a fase entre 3 e 6 anos, nomeada de personalismo, se caracteriza como um período de construção de si como um ser diferente de outros seres; um processo de discriminação eu-outro. A criança desta idade necessita ao mesmo tempo se opor ao outro, expulsando-o de si; seduzir e imitar, para assimilá-lo e reelaborar sua personalidade única e total [...]. Nesse processo, a consciência corporal e a vivência de movimentos são fatores que permearão o conhecimento de si, não só quando criança, mas ao longo da vida.

Brincar, correr e se movimentar em diferentes espaços, recriando e reinventandose, explorando as infinitas possibilidades de vivência da corporeidade, encontram acolhida com o ser criança, bem como na dança, a mais antiga forma de arte. Como potência de vida e expressão artística, a dança associada ao brincar permite à criança compreender o mundo que a cerca pela fruição e não por imposição e imobilidade. Como pontua Cebulski (2014), a atividade artística pode proporcionar a apreensão do mundo e promover o enlace do âmbito afetivo com o cognitivo.

Em seus estudos sobre o movimento, Laban (1978) percebe que mesmo acompanhando o ritmo da música podia-se notar as diferenças entre os gestos corporais das pessoas, pois os movimentos tinham impulsos internos diferenciados. Assim, 
desenvolveu o que hoje pode ser chamada de base para a dança moderna e seus ensinamentos ultrapassaram seu tempo. A dança pedagógica de Laban pode ser feita de maneira que diferentes corpos usufruam da prática, sendo mais importante compreender o movimento em sua dimensão expressiva: "Assim, o treinamento corporal de Laban volta-se muito mais às questões estruturais do movimento, procurando fazer com que o aluno se torne consciente das relações entre seu corpo e o espaço" (GUIMARÃES, 2006, p. 44).

Podemos reconhecer que a dança é para Laban a possibilidade de os indivíduos conhecerem seus corpos, reconhecerem seus movimentos, sensações, expressarem-se das mais variadas formas. A dança que Laban apresenta considera a biografia de cada pessoa e proporciona a liberdade de movimento próprio, acarretando em desenvolvimento não apenas físico, mas também emocional e social. Entretanto, para vislumbrar a sobrevivência de tal concepção e práticas nas instituições é imprescindível o desemparedamento das crianças com atividades em espaços externos, muitas brincadeiras que possibilitem vivências integrativas e com significado para elas.

Para subverter as práticas instituídas que se manifestam nas atividades realizadas, na organização empobrecida e pouco lúdica dos espaços e nas verbalizações que expõem as relações de poder, torna-se imprescindível a formação de professores em uma perspectiva que valorize a Educação Infantil como momento de aprendizagens e descobertas, em que a criança aparece como protagonista. As linguagens expressivas infantis não se resumem à escrita ou à fala, e a dança é potente para fazer o corpo falar:

Ressaltamos a necessidade de que a dança, e toda a sua dimensão cultural e lúdica, possa integrar os espaços de formação de professores de crianças, aqui em específico a Pedagogia, para que possamos questionar, refletir os sentidos e possibilidades do corpo em movimento, para que outras propostas possam ser desenvolvidas a partir da dança nos espaços educativos, com maior sentido e significado (GALVÃO; CAMARGO, 2020, p. 302).

Da condição do corpo como objeto de controle, defendemos o deslocamento para valorizar os movimentos manifestos nas relações das crianças entre si e com os adultos que com elas trabalham. Como registram Santos, Guimarães e Arenhart (2019, p. 508), "Os sentidos mobilizados pelo corpo nesses encontros passam por afeto, força, cuidado, cumplicidade, resistência, confiança, poder e controle".

Sair do recolhimento e proporcionar a soltura dos corpos representa um ato de resistência que a dança pode proporcionar. Como salientam Galvão e Camargo (2020), a dança provoca reflexões sobre os sentidos e possibilidades do corpo em movimento, 
promove a compreensão da cultura e da diversidade, expressa sentimentos e emoções. As autoras defendem que a articulação entre dança e brincadeiras atua sobre o conhecimento do corpo, seus limites e potencialidades e contribui para a tomada de decisões, a manifestação de desejos, atraindo as crianças e envolvendo-as nas propostas.

Ao brincar e dançar com as crianças os professores, nas instituições educativas, valorizam a potência do corpo e da corporeidade nas práticas e vivências, alimentam o corpo brincante, corpo-potência, dando a ele seu devido valor (LÓPEZ-LÓPEZ; GALDINO, 2020). Abraçar uma proposta de educação das crianças pequenas nessa direção acolhe a infância e respeita seu fazer e seu corpo pulsante.

\section{Considerações finais}

Elemento primordial de nossa vivência, o corpo é atravessado por diversas experiências e práticas desde que nascemos, e problematizar como isso acontece nos contextos escolarizados é de suma importância. O controle dos corpos infantis tem sido empreendido desde longa data pelas instituições educativas, e o tempo presente reafirma essa intenção e coloca em ação outras estratégias, especialmente centradas em vocalizações que desqualificam, constrangem e limitam a criança. Os contextos investigados apresentam suas particularidades, o que não permite generalizações, contudo, é imperioso pensar sobre nossas intencionalidades nos processos educativos com as crianças pequenas e as racionalidades que orientam nossas ações e escolhas.

Considerar a criança a partir de suas múltiplas linguagens e como um sujeito capaz, que interage, pensa, inventa e descobre, sustenta práticas que acolhem a potência dos corpos infantis. A Educação Infantil tem objetivos e finalidades que não a subordinam aos anos posteriores da escolarização, por isso transformar o corpo-criança em corpo-aluno desconsidera o que os sujeitos são e dá lugar a uma pré-escola preparatória em suas práticas e controladora em seus encaminhamentos normativos.

Frente ao cotidiano regulado e constritivo, a dança é reconhecida como a oportunidade de aprender por meio das experimentações, configurando-se como uma forma de falar com o corpo inteiro e atuando na promoção de uma educação que contribui para a formação de crianças e adultos críticos e conscientes de si e da sua cultura. Como ressalva Marques (2007), pela dança podemos colocar em prática abordagens pedagógicas conectadas com a diversidade das realidades sociais e a 
atualidade, as quais não são estáticas. Configura-se, nesse sentido, a dança como uma pedagogia vital que se conecta com a vida das crianças, incluindo sua temporalidade e abarcando seus repertórios pessoais, acolhendo-as e valorizando-as como sujeitos de direito que são.

Em uma sociedade que cada vez mais cedo as crianças frequentam instituições educativas, estas precisam ser o primeiro caminho para a emancipação, por meio de uma formação humanizada e não alienada. O professor tem o papel de articulador, que ao propor jogos em dança educativa, dança criativa ou livre, pode por meio das escolhas feitas pelas crianças, falar sobre os corpos que dançam e os corpos na dança. Relações que a uma primeira vista podem parecer ingênuas ou simples, têm potencial para se tornarem experiências críticas. Os aprendizados que decorrem das experimentações em dança revelam a importância de um professor preparado para ensinar dança, caso contrário, a experiência se torna vazia, estereotipada, destituída de sentido.

Nestes contextos, que de fato não podem prescindir da organização pois lidam com a coletividade, a disciplina não pode apagar, silenciar, anular as particularidades e necessidades infantis, o corpo pulsante potência de vida das crianças. A corporeidade vivida na apropriação da cultura em contextos, nos quais as relações e os vínculos sejam fortalecidos colaboram para a concepção de criança como um sujeito que cria, inventa, narra, produz cultura e encontre morada.

\section{Referências}

ALMEIDA, F. S. A dança e a criança de Educação Infantil: um caminho de aproximação. São Paulo, 2011. Não paginado.

BARBOSA, C. J.; BORBA, M. T. P. de. Silêncio dentro da sala de aula. Entreideias, Salvador, n. 20, p. 83-98, jul./dez. 2011. Disponível em: https://portalseer.ufba.br/index.php/entreideias/article/view/3611. Acesso em: 02 mar. 2021.

BONFIM, P. V.; OSTETTO, L. E. Para pensar o apagamento ritualizado dos corpos na creche: adultos, bebês, atividades. Artes de Educar, Rio de Janeiro, v. 5, n. 3, p. 491507, 2019. Disponível em: https://www.epublicacoes.uerj.br/index.php/riae/article/view/45278/31551. Acesso em: 02 mar. 2021.

BRASIL. Lei n. 9.394, de 20 de dezembro de 1996. Estabelece as diretrizes e bases da educação nacional. Diário Oficial da União, Brasília, DF, 23 dez. 1996.

BRASIL. Diretrizes Curriculares Nacionais para a Educação Infantil. Ministério da Educação. Secretaria de Educação Básica. Brasília, DF: MEC, 2009.

Revista Digital do LAV - Santa Maria - vol. 14, n. 3, p. 83 - 106 - set./dez. 2021 ISSN 1983 - 7348 http://dx.doi.org/10.5902/1983734864933 
CARVALHO, R. S. de. Educação Infantil: práticas escolares e o disciplinamento dos corpos. Dissertação (Mestrado em Educação) - Programa de Pós-Graduação em Educação, Porto Alegre, UFRGS. 2005.

CEBULSKI, M. C. Um diálogo entre Vygotsky e o sistema teórico da afetividade ampliada: o teatro na educação básica e o desenvolvimento sócio emocional humano. Tese (Doutorado em Educação). Setor de Educação, Universidade Federal do Paraná. 2014.

COLELLO, S. M. G. Alfabetização e motricidade: revendo essa antiga parceria. Cadernos de Pesquisa, São Paulo, n. 87, p. 58-61, nov. 1993. Disponível em: http://publicacoes.fcc.org.br/ojs/index.php/cp/article/view/927. Acesso em: 02 mar. 2021.

FOUCAULT, M. Microfísica do poder. Organização e tradução de Roberto Machado. Rio de Janeiro: Graal, 2005.

FOUCAULT, M. Vigiar e punir: o nascimento da prisão. Tradução de Raquel Ramalhete. Petrópolis: Vozes, 1999.

GALVÃO, P. T.; CAMARGO, D. A dança na prática pedagógica com crianças: olhares e reflexões de uma professora em formação. Artes de Educar, Rio de Janeiro, v. 6, n. 1, p. 302-323, 2020. Disponível em: https://www.epublicacoes.uerj.br/index.php/riae/article/view/45838/32180. Acesso em: 02 mar. 2021.

GUIMARÃES, M. C. A. Rudolf Laban: uma vida dedicada ao movimento. In: MOMMENSOHN, M.; PETRELLA, P. (Orgs.). Reflexões sobre Laban: o mestre do movimento. São Paulo: Summus, 2006.

HORN, M. da G. S. Brincar e interagir nos espaços da escola infantil. Porto Alegre: Penso, 2017.

KISHIMOTO, T. M. O brincar e suas teorias. São Paulo: Pioneira-Thomson Learning, 2002.

KOHAN, W. O. A infância da Educação: o conceito devir-criança. 2003. Disponível em: www.educacaopublica.rj.gov.br/biblioteca/educacao/0184.html. Acesso em: 02 mar. 2021.

LABAN, R. Dança educativa moderna São Paulo: Ícone, 1990.

LABAN, R. Domínio do movimento. São Paulo: Summus, 1978.

LAVAL, C. Foucault, Bourdieu e a questão neoliberal. São Paulo: Elefante, 2020.

LIRA, A. C. M. Pedagogização da infância: refletindo sobre poder e regulação. InterAção, Goiânia, v. 2, n. 33, p. 317-341, jul./dez. 2008. Disponível em: https://www.revistas.ufg.br/interacao/article/view/5270. Acesso em: 02 mar. 2021.

LIRA, A. C. M.; DREWINSKI, J. M. de A.; SAPELLI, M. L. S. Educação Infantil para crianças de quatro e cinco anos: entre a obrigatoriedade, o direito e a imposição. Imagens da Educação, Maringá, v. 6, n. 2, p. 84-97, 2016. Disponível em: http://periodicos.uem.br/ojs/index.php/ImagensEduc/article/view/27947. Acesso em: 02 mar. 2021.

Revista Digital do LAV - Santa Maria - vol. 14, n. 3, p. 83 - 106 - set./dez. 2021 ISSN 1983 - 7348 http://dx.doi.org/10.5902/1983734864933 
LÓPEZ-LÓPEZ, M. A.; GALDINO, G. R. A potência do corpo e da corporeidade nas práticas e vivências educativas. Artes de Educar, Rio de Janeiro, v. 6, n.1, p. 129-140, 2020. Disponível em:

https://www.epublicacoes.uerj.br/index.php/riae/article/view/45830/32166. Acesso em: 02 mar. 2021.

LUENGO, F. C. A vigilância punitiva: a postura dos educadores no processo de patologização e medicalização da infância. [E-book]. São Paulo: UNESP/Cultura Acadêmica, 2009. Disponível em: http://books.scielo.org/id/sw26r/pdf/luengo9788579830877.pdf. Acesso em: 02 mar. 2021.

MARQUES, I. M. M. de A. Dança e Educação. Revista da Faculdade de Educação, São Paulo, v. 18, p. 5-22, jan./dez. 1990. Disponível em: http://www.revistas.usp.br/rfe/article/view/33450. Acesso em: 02 mar. 2021.

MARQUES, I. M. M. de A. Dançando na escola. 4ºd. São Paulo: CORTEZ, 2007.

OLIVEIRA, D. A música como instrumento de poder. Jundiaí: PACO, 2011.

PERROTTI, E. A criança e a produção cultural. In: ZILBERMAN, R. (Org). A produção cultural para a criança. 4. ed. Porto Alegre: Mercado Aberto, 1990.

QUEIROZ, N. L. N.; MACIEL, D. A.; BRANCO, A. U. Brincadeira e desenvolvimento infantil: um olhar sociocultural construtivista. Paidéia, Ribeirão Preto, v. 16, n. 34, 169179, 2006. Disponível em: https://www.scielo.br/pdf/paideia/v16n34/v16n34a05.pdf. Acesso em: 02 mar. 2021.

SABOT, P. O que é uma sociedade disciplinar? Gênese e atualidade de um conceito, a partir de Vigiar e Punir. DoisPontos, Curitiba, v. 14, n. 1, nov. 2017. Disponível em: https://revistas.ufpr.br/doispontos/article/view/56536. Acesso em: Acesso: 02 mar. 2021.

SANTOS, A. C. R. F. dos. Corporeidade infantil: quando o corpo- criança é transformado no corpo-aluno. 2020. 104f. Dissertação (Mestrado em Educação) Universidade Estadual do Centro-Oeste, Guarapuava, 2020.

SANTOS, A. S dos; GUIMARÃES, D.; ARENHART, D. Corpos cheios de si e do outro: encontros entre crianças e adultos na creche. Artes de Educar, Rio de Janeiro, v. 5, n.3, p. 508-524, 2019. Disponível em: https://www.epublicacoes.uerj.br/index.php/riae/article/view/45803/31552. Acesso em: 02 mar. 2021.

SERÓDIO, S. C. F.; STEINLE, M. C. B. A importância da organização do espaço para atender o aluno do $1^{\circ}$ ano do ensino fundamental de nove anos. Anais da XVI Semana da Educação, Londrina, 2016. Disponível em: www.uel.br/eventos/semanadaeducacao/pages/anais/2015.php. Acesso em: 02 mar. 2021.

SILVA, A. F. F. da; SANTOS, E. C. M. dos. A importância do brincar na Educação Infantil. Curso de especialização "Desafios do trabalho cotidiano: a educação das crianças de 0 a 10 anos". Rio de Janeiro, 2009.

STRAZZACAPPA, M. A educação e a fábrica de corpos: a dança na escola. Cadernos Cedes, Campinas, ano XXI, n. 53, abril 2001. Disponível em: www.scielo.br/pdf/ccedes/v21n53/a05v2153.pdf. Acesso em: 02 mar. 2021. 
VEIGA-NETO, A. Crise da modernidade e inovações curriculares: da disciplina para o controle. Sísifo/Revista de Ciências da Educação, Lisboa, n. 7, p. 141-149, set./dez. 2008. Disponível em: https://madmunifacs.files.wordpress.com/2016/04/veiga-netomodernidade-e-curriculos.pdf. Acesso em: 02 mar. 2021.

WAHBA, L. L.; SCHMITT, P. S. A criança e a dança: observação clínica em grupo sobre o processo de individuação. Boletim Academia Paulista de Psicologia, São Paulo, v. 33, n. 85, p. 427-445, $2013 . \quad$ Disponível em: http://pepsic.bvsalud.org/scielo.php?script=sci_abstract\&pid=S1415$711 \times 2013000200014 \&$ lng=pt\&nrm=iso. Acesso em: 02 mar. 2021.

i Mestre em Educação pela Universidade Estadual do Centro-Oeste - UNICENTRO. Integrante do Grupo de Estudos e Pesquisas em Educação Infantil- GEPEDIN/CNPq.

ii Pós-doutorado em Educação pela Universidade Estadual de Maringá (UEM). Doutora e Mestre em Educação pela Universidade de São Paulo (USP). Professora Associada do Departamento de Pedagogia e do Programa de Pós-Graduação em Educação da Universidade Estadual do Centro-Oeste/UNICENTRO, Guarapuava/PR. Líder do Grupo de Estudos e Pesquisas em Educação Infantil - GEPEDIN/CNPq/UNICENTRO.

Como citar esse artigo:

SANTOS, Aline Cristiane Ribeiro Ferreir; LIRA, Aliandra Cristina Mesomo. Do CorpoCriança ao Corpo-Aluno: Estratégias de Controle e Possibilidades de Resistência pela Dança na Educação Infantil. Revista Digital do LAV, Santa Maria: UFSM, v. 14, n. 3, p. 83-106, set./dez. 2021. 